\title{
Unveiling the Shape Evolution and Halide-Ion-Segregation in Blue- Emitting Formamidinium Lead Halide Perovskite Nanocrystals Using an Automated Microfluidic Platform
}

\author{
Ioannis Lignos, ${ }^{\dagger, \|_{\odot}}$ Loredana Protesescu, ${ }^{\dagger, \S, \perp \odot 0}$ Dilara Börte Emiroglu, ${ }^{\dagger}$ Richard Maceiczyk, ${ }^{\dagger}$
}

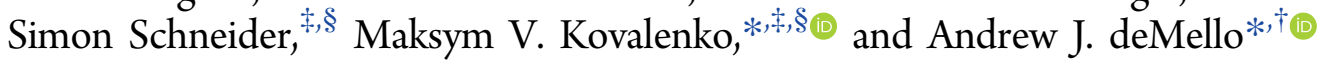

${ }^{\dagger}$ Department of Chemistry and Applied Biosciences, Institute for Chemical and Bioengineering, ETH Zürich, Vladimir-Prelog-Weg 1, Zurich 8093, Switzerland

${ }^{\ddagger}$ Department of Chemistry and Applied Biosciences, Institute of Inorganic Chemistry, ETH Zürich, Vladimir-Prelog-Weg 1, Zurich 8093, Switzerland

${ }^{\S}$ Empa-Swiss Federal Laboratories for Materials Science and Technology, Überlandstrasse 129, Zurich 8600, Switzerland

Supporting Information

ABSTRACT: Hybrid organic-inorganic perovskites and in particular formamidinium lead halide $\left(\mathrm{FAPbX}_{3}, \mathrm{X}=\mathrm{Cl}, \mathrm{Br}, \mathrm{I}\right)$ perovskite nanocrystals (NCs) have shown great promise for their implementation in optoelectronic devices. Specifically, the $\mathrm{Br}$ and I counterparts have shown unprecedented photoluminescence properties, including precise wavelength tuning $(530-790 \mathrm{~nm})$, narrow emission linewidths $(<100 \mathrm{meV})$ and high photoluminescence quantum yields (70-90\%). However, the controlled formation of blue emitting $\mathrm{FAPb}\left(\mathrm{Cl}_{1-x} \mathrm{Br}_{x}\right)_{3} \mathrm{NCs}$ lags behind their green and red counterparts and the mechanism of their formation remains unclear. Herein, we report the formation of $\mathrm{FAPb}\left(\mathrm{Cl}_{1-x} \mathrm{Br}_{x}\right)_{3} \mathrm{NCs}$ with stable emission between 440

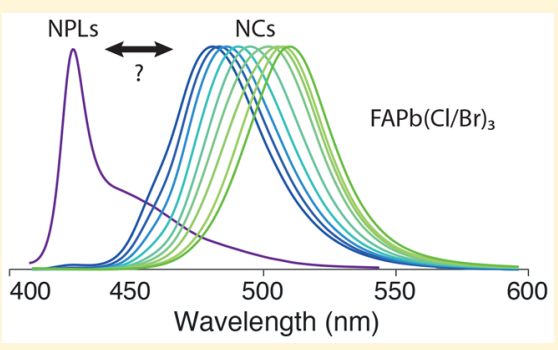
and $520 \mathrm{~nm}$ in a fully automated droplet-based microfluidic reactor and subsequent reaction upscaling in conventional laboratory glassware. The thorough parametric screening allows for the elucidation of parametric zones (FA-to- $\mathrm{Pb}$ and $\mathrm{Br}$-to- $\mathrm{Cl}$ molar ratios, temperature, and excess oleic acid) for the formation of nanoplatelets and/or NCs. In contrast to $\mathrm{CsPb}\left(\mathrm{Cl}_{1-x} \mathrm{Br}_{x}\right)_{3} \mathrm{NCs}$, based on online parametric screening and offline structural characterization, we demonstrate that the controlled synthesis of $\mathrm{Cl}$-rich perovskites (above 60 at\% $\mathrm{Cl}$ ) with stable emission remains a challenge due to fast segregation of halide ions.

KEYWORDS: Perovskites, lead halide, formamidinium, nanocrystals, microfluidics, nanoplatelets

T ead halide perovskite nanocrystals (LHP NCs) have received enormous attention as luminescent materials for a wide variety of applications, ${ }^{1-9}$ including photovoltaics, ${ }^{10-12}$ displays, ${ }^{13-17}$ light-emitting diodes (LEDs), ${ }^{18-23}$ and lasing. $^{24,25}$ The main and peculiar advantages of such materials, compared to traditional chalcogenide quantum dots (QDs), include (i) facile bandgap tuning by composition (through choice of halide and halide mixtures) and (ii) extremely highphotoluminescence (PL) quantum yields (QYs, 20 and 90\%) achievable without the need for electronic surface passivation with wider-gap epitaxial shells. ${ }^{13,26}$ This high emissivity is attributed to the unusually high defect tolerance of LHPspoint defects and surfaces do not reside within the bandgap and therefore do not quench the radiative recombinations of photoexcited carriers. ${ }^{27-29}$ Their PL is characterized by narrow emission line widths of $<100 \mathrm{meV}$ (also known as the full width at half-maximum, fwhm) throughout the whole visible range. This provides for superior color performance for display applications, in particular, green emission (with QYs above $90 \%$ ) and with fwhm values less than $40-45 \mathrm{~nm}$ at $640 \mathrm{~nm}$, thus covering up to $140 \%$ of the NTSC color gamut. In displays, LHP NCs can be used in backlighting to convert blue light from the $\mathrm{GaN}$ diodes into green and red light.

As with more conventional emitters (such as QDs, organic molecules, and phosphors), access to the blue-to-green spectral region remains particularly challenging for LHP NCs. ${ }^{4}$ For instance, although blue-emitting chalcogenide QDs, ${ }^{30-32}$ such as $\mathrm{ZnCdS}$ core/multishell NCs, exhibit high QYs of up to $90 \%$, QD LEDs constructed from such materials exhibit rather small external quantum efficiencies (EQEs), reportedly remaining below $10 \% .^{33,34}$ Reasons for the reduced performance of blue QD emitters are both device-related (i.e., associated with the difficulty in selecting suitable hole and electron transporting layers) and, more importantly, inherent to the QD materials. Put simply, the higher the bandgap, the more severe are the difficulties in synthesizing emissive QDs and in retaining their optical and chemical integrity when integrated within LED constructs. $^{30,34,35}$

Received: November 15, 2017

Revised: January 11, 2018

Published: January 16, 2018 

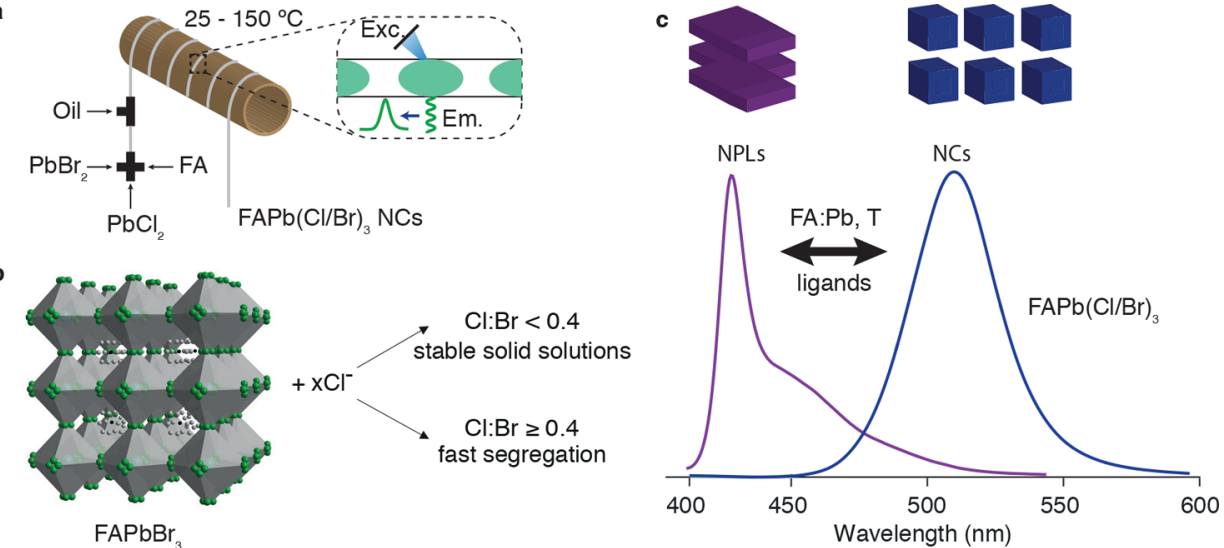

Figure 1. (a) Schematic of the droplet-based microfluidic reactor with online fluorescence detection. Precursors are mixed in a cross-junction and enter together with a perfluorinated carrier fluid in a T-junction where they are compartmentalized into nanoscale droplets. After they enter a heating-zone, they are excited by a $365 \mathrm{~nm}$ LED and the emission is collected and analyzed using a spectrometer. (b) Crystal structure of a threedimensional cubic $\alpha$ - $\mathrm{FAPbBr}_{3}$ with orientational disorder of the $\mathrm{FA}$ molecules and split positions of bromide atoms, ${ }^{36,37}$ and its conversion into mixed-halide $\mathrm{FAPb}\left(\mathrm{Cl}_{1-x} \mathrm{Br}_{x}\right)_{3} \mathrm{NCs}$ for lower $\mathrm{Cl}$ loadings or the fast halide-ion segregation after overloading with $\mathrm{Cl}$ ions by anion-exchange. (c) $\mathrm{A}$ conceptualization of the interplay between the reaction parameters and the resulting shape of $\mathrm{NCs}(\mathrm{NPLs})$. Competition between $\mathrm{FAPb}\left(\mathrm{Cl}_{1-x} \mathrm{Br}_{x}\right)_{3}$ $\mathrm{NPLs}$ and NCs after a high-throughput microfluidic screening of reaction parameters. The critical regulated parameters are $\mathrm{FA}$-to-Pb molar ratio, temperature, and the concentration of ligands.

Subsequent to the development of the hot-injection synthesis of uniform colloidal cesium-based LHP NCs $\left(\mathrm{CsPbX}_{3}, \mathrm{X}=\mathrm{Cl}\right.$, $\mathrm{Br}, \mathrm{I})$ of the cubic shape, ${ }^{13}$ the synthesis was further refined with regard to precursors/ligands and the methods of mixing and heating. ${ }^{38-41}$ Notable advancements in this respect include the shape-engineered synthesis of nanowires (NWs) ${ }^{42-44}$ and nanoplatelets (NPLs), ${ }^{45-49}$ postsynthetic cation and anion exchange, ${ }^{50,51}$ characterization of reaction kinetics, ${ }^{52,53}$ surface engineering $^{54,55}$ and doping. ${ }^{56-60}$

Recently, perovskite NCs with formamidinium $\left[\mathrm{CH}\left(\mathrm{NH}_{2}\right)^{+}\right.$, FA] as an A-cation alternative to $\mathrm{Cs}^{+}$have attracted much attention. ${ }^{37,46,61-63}$ Monodisperse $\mathrm{FAPbBr}_{3}$ NCs, for instance, exhibit emission peaks between 530 and $535 \mathrm{~nm}$, fwhm values below $22 \mathrm{~nm}$ and high PL QYs (85\%). ${ }^{37}$ FA-compositions have proved to be chemically more robust than their methylammonium ( $\mathrm{MA}, \mathrm{CH}_{3} \mathrm{NH}_{3}^{+}$)-based counterparts. In the case of iodides, FA analogues overcome limitations related to the instability of the three-dimensional (3D)-perovskite polymorph of $\mathrm{CsPbI}_{3} \mathrm{NCs}^{64-67}$ Other efforts aimed at forming stable and color tunable FA-based LHP NCs have focused on anion (Clto-Br-to I) and cation (Cs to FA) substitutions. ${ }^{6,64-70}$ In these studies, FA-based LHP NCs with tunable emission between 415 and $740 \mathrm{~nm}$ and with QYs up to $85 \%$ were synthesized. $\mathrm{Cl}$ and $\mathrm{Cl}_{0.5} / \mathrm{Br}_{0.5}$ compositions exhibit QYs of $1-26 \%$. It should however be noted that for the region between 450 and $530 \mathrm{~nm}$ (e.g., Br-rich compositions), very limited information regarding PL tuning, stability, and the factors governing these parameters can be found in the literature. Indeed, practically nothing is known about the shape-engineering of FA-based NCs, apart of atomically thin platelets, such as those reported by Tisdale et al. $46,71,72$

Herein, we explore the formation of $\mathrm{FAPb}\left(\mathrm{Cl}_{1-x} \mathrm{Br}_{x}\right)_{3} \mathrm{NCs}$ and NPLs using an automated droplet-based microfluidic platform (Figure 1a, and for a description of the experimental setup and synthetic procedures see Supporting Information, SI) that allows for the high-throughput assessment of reaction mechanisms using online collected PL spectra. Moreover, the synthesis parameters extracted from the microfluidic platform were transferred to a hot-injection synthesis for upscaling the production of mixed $\mathrm{Cl} / \mathrm{Br}$ NCs. Herein, we discuss the screening of parametric spaces ( $\mathrm{Br}$ addition, temperature, and molar ratios of precursors) in terms of the formation of NCs and/or NPLs and highlight synthetic challenges for obtaining stable blue emitters.

A thorough and quantitative investigation of a multiparametric system requires efficient mapping within an acceptable time scale. For the system of interest, which is characterized by the rapid nucleation and growth of NCs, such efficient screening can be achieved using microfluidic systems with integrated analytical systems. ${ }^{52,73-79}$ Such platforms provide for the rapid mixing of precursor solutions as well as fast heating and thus are well-suited for elucidating reaction mechanisms in multicomponent systems; particularly those with rapid reaction kinetics. ${ }^{80-82}$ In addition, they are exceptionally powerful in providing real-time information regarding the size, shape, chemical composition, and sizedistribution of the synthesized compounds. ${ }^{80}$

In the current studies, two synthetic methods were employed. The first using $\mathrm{PbBr}_{2}$ and $\mathrm{PbCl}_{2}$ as both lead and halide sources (method 1 ), and the second using oleylammonium bromide (OLAmBr) and chloride (OLAmCl) precursors (method 2) as a source of halides ${ }^{37}$ (see Supporting Information for further details). In the latter, $\mathrm{Pb}$ (oleate) $)_{2}$ was used as $\mathrm{Pb}^{2+}$ precursor. The microfluidic platform (Figure 1a) allows for fine-tuning of interlinked molar ratios of precursors to adjust particle compositions. In particular, for method 1 there are two independently adjustable parameters, $\mathrm{FA} / \mathrm{Pb}$ and $\mathrm{Br} / \mathrm{Cl}$ molar ratios ( $\mathrm{Cl}$ or $\mathrm{Br}$ loading), whereas method 2 includes an additional independent variable, the $\mathrm{Pb} /(\mathrm{Br}+\mathrm{Cl})$ molar ratio. The reaction time was kept constant $(7 \mathrm{~s})$ in all experiments to ensure stabilization of the PL wavelengths and $\mathrm{PL}$ intensities of $\mathrm{FAPbX}_{3} \mathrm{NCs}$, typically after $3-5 \mathrm{~s}$ when NC size reaches the regime of weak confinement (typically above 8 $\mathrm{nm}) .{ }^{83}$ We also note that attempts to capture the formation of smaller NCs are impractical, because such NCs are structurally unstable and always evolve into larger NCs.

There are several key differences between perovskite NPLs and NCs. NPLs exhibit much narrower emission linewidths 
(fwhm values of 8-10 nm, compared to more than $20 \mathrm{~nm}$ for cubes). Additionally, their PL spectra evolve in discrete steps according to the number of perovskite unit cells fitted in the NPL thickness. Their absorption features are also narrower and more pronounced, due to a large oscillator strength associated with band edge transitions. ${ }^{46,48,49}$ In particular, $\mathrm{L}_{2}\left[\mathrm{FAPbX}_{3}\right]_{n-1} \mathrm{PbX}_{4}$ NPLs, where L is $\mathrm{OLAm}^{+}$and $n=1,2$, and 3 (number of unit cells in thickness), were recently reported by Weidman et al. For $\mathrm{L}_{2}\left[\mathrm{FAPbBr}_{3}\right]_{\mathrm{n}-1} \mathrm{PbBr}_{4}$ with $n=$ 1 and $n=2$, PL peak positions are located at 403.2 and $439 \mathrm{~nm}$, respectively. ${ }^{46}$ It is expected that the ligand concentration $\left(\mathrm{OLAm}^{+}\right)$and the relative ratios of $\mathrm{FA}$ and $\mathrm{Pb}$ sources will promote either the formation of NCs or NPLs.

Systematic variation of the synthesis temperature between 35 and $150{ }^{\circ} \mathrm{C}$ in method $1(\mathrm{FA} / \mathrm{Pb}$ molar ratio is set to 5.7$)$ indicates that a temperature of $130{ }^{\circ} \mathrm{C}$ is best suited for all NC compositions, based on assessment of fwhm values (Figure 2).
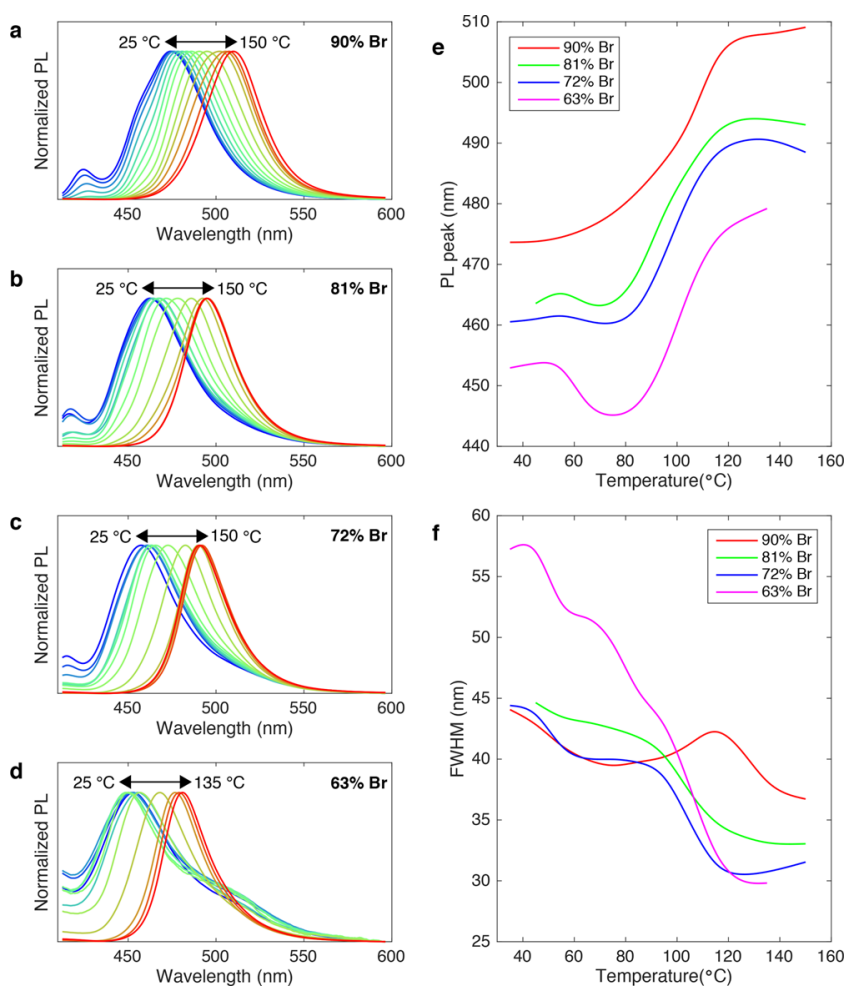

Figure 2. Variation of (a-d) emission spectra, (e) PL maxima, and (f) fwhm of $\mathrm{FAPb}\left(\mathrm{Cl}_{1-x} \mathrm{Br}_{x}\right)_{3} \mathrm{NCs}$ as a function of temperature $(25-150$ $\left.{ }^{\circ} \mathrm{C}\right)$. Br loading was varied between 63 and $90 \%$. Colors in $(\mathrm{e}, \mathrm{f})$ correspond to various $\mathrm{Br}$ loadings indicated in the corresponding legend. Other parameters were $\mathrm{FA} / \mathrm{Pb}=5.7$ and a reaction time of $7 \mathrm{~s}$.

Lower temperatures lead to significantly broader PL bands and the concurrent formation of NPLs and NCs, whereas higher temperature cause thermal decomposition of the product, evidenced by a dramatic drop in the PL intensity. Thermal decomposition of the FA cations, for example, may lead to the formation of ammonium cation (and release of $\mathrm{HCN})^{84}$ as previously observed for $\mathrm{FAPbBr}_{3} \mathrm{NCs}\left(\mathrm{NH}_{4} \mathrm{~Pb}_{2} \mathrm{Br}_{5}\right.$ was identified as an impurity). ${ }^{37}$ Analogous temperature-dependent results of method 2 are presented in Figure S1, wherein an optimal temperature range of $110-135{ }^{\circ} \mathrm{C}$ was identified. However, Figure $2 \mathrm{a}-\mathrm{c}$ highlight that at high $\mathrm{Br} \%(72-90 \%)$ and at low temperatures (less than $75{ }^{\circ} \mathrm{C}$ ) the synthesized particles exhibit two emission bands, NPL-like emission (between 410 and $425 \mathrm{~nm}$ ) and NC-like emission (cubic structure, between 450 and $520 \mathrm{~nm}$ ). Importantly, the relative intensities of these component peaks vary according to the incorporated $\mathrm{Br}$ content. Above $75{ }^{\circ} \mathrm{C}$, emission originates predominantly from the NCs, reaching a maximum above 120 ${ }^{\circ} \mathrm{C}$, where particle growth stops (Figure S2).

Comparison of the temperature-dependent PL spectra of $\mathrm{FAPb}\left(\mathrm{Cl}_{1-x} \mathrm{Br}_{x}\right)_{3} \mathrm{NCs}$ after employing method 1 (Figure 1) and method 2 (Figure S1) highlights two important differences. First, the observed reaction kinetics in method 2 are faster than in method 1 , because PL peak positions remain constant for temperatures above $80^{\circ} \mathrm{C}$ (Figure S1). Second, using method 2 and for temperatures below $75{ }^{\circ} \mathrm{C}$, three bands of emission are apparent in the PL spectra: two discrete NPL PL bands (432 and $462 \mathrm{~nm}, n=2$ and possibly $n=3$ NPLs, respectively) and one NC-like emission. Such variations can be attributed to the difference in the concentration of capping ligands employed in the two methods and to the additional tunable parameter, $(\mathrm{Pb} /$ $(\mathrm{Br}+\mathrm{Cl})$ employed in method 2 , which provides a more stoichiometric control over the resulting crystals

To further decouple the effects of stoichiometry and temperature on the observed emission, we conducted various reactions under $\mathrm{Pb}$-rich conditions $(0.3<\mathrm{FA} / \mathrm{Pb}<1.7$, Figure $\mathrm{S} 3)$ and at room temperature. In general, higher $\mathrm{Pb}$ content favored the formation of NPLs emitting at $420 \mathrm{~nm}$, suppressing NC-like emission (Figure 3a). However, the isolation of NPLs, at least with the reaction conditions applied, was nearly impossible because of the fast decomposition process, particularly those with a thickness of $1-2$ monolayers. This reaction path is induced by the excess of $\mathrm{Pb}$ precursor, which favors the concurrent formation of the higher content $\mathrm{Pb}$

\section{Reaction conditions for the synthesis of $\mathrm{FA}(\mathrm{Cl} / \mathrm{Br})_{3}$ nanocubes:

$$
3 \mathrm{PbX}_{2}+2 \mathrm{FA} \text { (oleate) } \underset{\mathrm{ODE}, \mathrm{TOP}}{\stackrel{[\mathrm{FA}: \mathrm{OLA}=2: 1}{\longrightarrow}} 2^{\mathrm{O} \mathrm{FAPbX}_{3}+\mathrm{Pb} \text { (oleate) }}{ }_{2}
$$

Reaction conditions for the formation of $\mathrm{Cl}-\mathrm{Br}$ nanoplatelets:
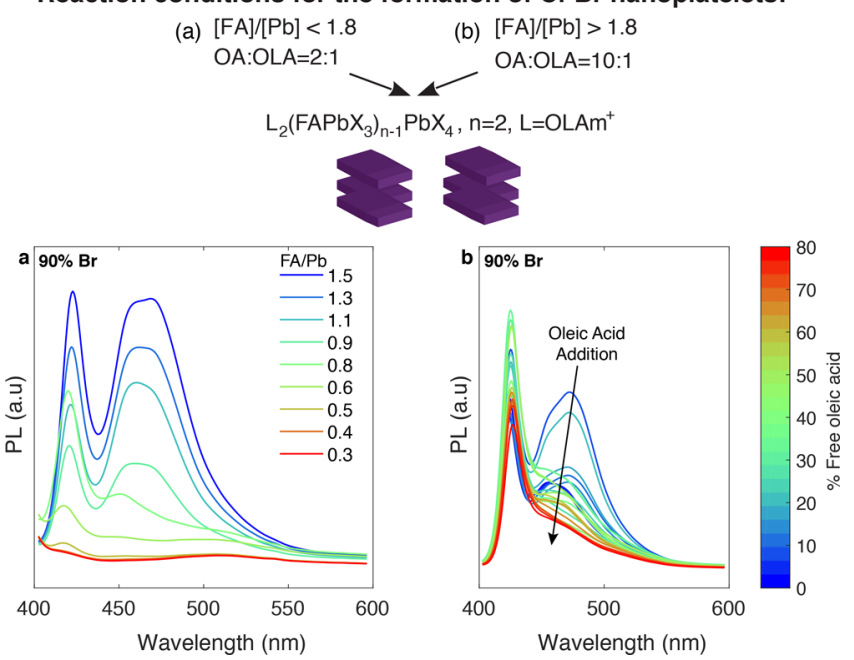

Figure 3. (a) Effect of $\mathrm{FA} / \mathrm{Pb}$ molar ratio on the $\mathrm{PL}$ of $\mathrm{FAPb}\left(\mathrm{Cl}_{1-x} \mathrm{Br}_{x}\right)_{3} \mathrm{NCs}$ (90\% $\mathrm{Br}$ loading). Colors correspond to various $\mathrm{FA}$ loadings and are indicated in the corresponding legend. The temperature was maintained at $25^{\circ} \mathrm{C}$. (b) Evolution of NPL- and NC-like emission after the addition of free oleic acid to the reaction solution. Colors correspond to various OA loadings and are indicated in the colormap. The temperature $\left(25^{\circ} \mathrm{C}\right)$ and FA-to- $\mathrm{Pb}$ molar ratio $(\mathrm{FA} / \mathrm{Pb}=1.5)$ were kept constant. 

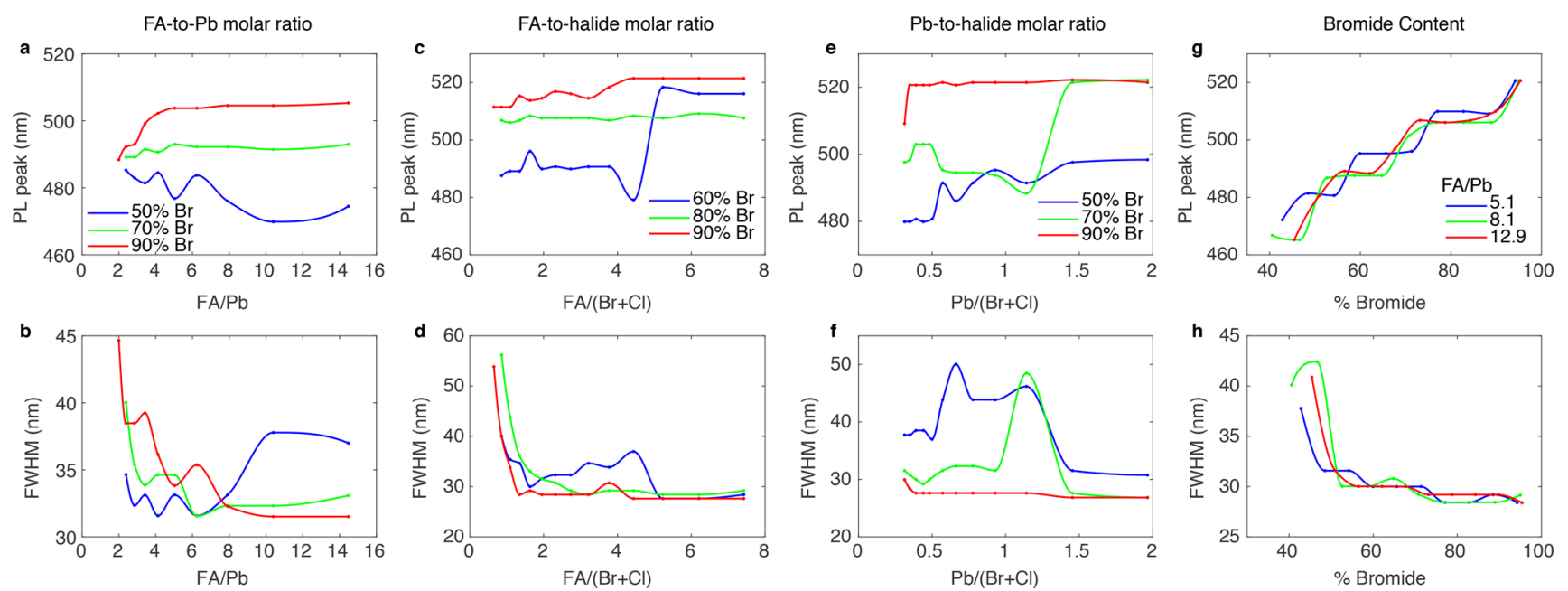

Figure 4. Effect of (a,b) FA-to-Pb molar ratio, (c,d) FA-to-total halide ratio, (e,f) Pb-to-total halide ratio, and (g,h) Br loading on PL spectra and fwhm of $\mathrm{FAPb}\left(\mathrm{Cl}_{1-x} \mathrm{Br}_{x}\right)_{3}$ perovskites. Colors in the PL spectra and data markers displayed in panels a-f and panels g,h correspond to various $\mathrm{Br}$ loadings and $\mathrm{FA}-$ to- $\mathrm{Pb}$ molar ratios that are indicated in the corresponding legends. The temperature $\left(130{ }^{\circ} \mathrm{C}\right)$ and reaction time $(7 \mathrm{~s})$ were maintained constant throughout.

compound, which corresponds to the formation of $\mathrm{L}_{2}\left[\mathrm{FAPbX}_{3}\right] \mathrm{PbX}_{4} \mathrm{NPLs}\left(\mathrm{L}=\mathrm{OLAm}^{+}\right)$. Importantly, identical behavior is apparent for various $\mathrm{Br} / \mathrm{Cl}$ perovskites (see Figure S3). To further suppress the formation of NCs at room temperature, we regulated the concentration of free oleic acid in the reaction system. Figure $3 \mathrm{~b}$ illustrates that addition of up to $80 \%$ of free oleic acid (with respect to the concentration of oleic acid species acting as a ligand during particle formation) in the reaction mixture further drives the reaction to form NPLs with a single emission peak at $420 \mathrm{~nm}$. It is likely that such behavior is due to greater activity of the OLAm ${ }^{+}$. Complex acidbased equilibria are present. $\mathrm{OLAm}^{+}$exists in equilibrium with OLA. When OA/OLA is increased, for instance, to $2: 1$, the equilibrium is shifted toward the protonation of the amine. However, when an additional oleate is introduced in the system in the form of FA(oleate), deprotonation of $\mathrm{OLAm}^{+}$can occur. This explains why the formation of $\mathrm{L}_{2}\left[\mathrm{FAPbX}_{3}\right] \mathrm{PbX}_{4} \mathrm{NPLs}$, with $\mathrm{L}$ being OLAm, is solely observed when the FA-to-Pb is below 1.8 (Figure 3a). On the other hand, when OA/OLA is much higher, a high yield of NPLs with $n=2$ is obtained (Figure $3 \mathrm{~b}$ ). Such a strategy for stabilizing $\mathrm{OLAm}^{+}$ligands, could allow for the isolation of NPLs with various $\mathrm{Br} / \mathrm{Cl}$ compositions, although this was not a specific goal of the current study. However, the ability to monitor the coexistence of NPLs using a droplet-based microfluidic system provides unique insights for the formation of NPL-free NC dispersions, such as (a) they are plausible products at the early stage of high-temperature reactions and (b) information on how to adjust synthetic parameters to avoid the formation of ultrathin and unstable NPLs. In fact, in some syntheses, the observed particles with irregular morphologies after particle purification are likely decomposition products of the synthesized NPLs.

To gain full control over mixed halide compositions in $\mathrm{FAPb}\left(\mathrm{Cl}_{1-x} \mathrm{Br}_{x}\right)_{3} \mathrm{NCs}$, we conducted a combinatorial study at $130{ }^{\circ} \mathrm{C}$ (where quantum confinement is weak) to identify the optimal molar ratios of precursors using both synthetic methods. Figure 4 demonstrates the dramatic effect of precursor molar ratios on PL characteristics. In particular, high $\mathrm{FA} / \mathrm{Pb}$ molar ratios (in the range of $5-10$ ) lead to $\mathrm{Cl} / \mathrm{Br}$ mixtures $(50-90 \% \mathrm{Br})$ with stable $\mathrm{PL}$ peak positions and minimum emission linewidths (Figure $4 \mathrm{a}, \mathrm{b}$ ). In addition, when applying method 2, interlinked molar ratios such as $\mathrm{FA} /(\mathrm{Br}+$ $\mathrm{Cl})$ and $\mathrm{Pb} /(\mathrm{Br}+\mathrm{Cl})$ should be maintained between 2.5 and 4 and 0.2 and 0.5 , respectively to synthesize $\mathrm{FAPb}(\mathrm{Cl} / \mathrm{Br})_{3} \mathrm{NCs}$ with the narrowest PL fwhm $(28 \mathrm{~nm}$, Figure $4 \mathrm{~d}, \mathrm{f}, \mathrm{h})$. Outside these windows, the PL characteristics of the synthesized NCs appear unstable, evidenced by rapid fluctuations in PL peak and fwhm (Figure 4c,e,f). After identifying the effects of all molar ratios and extracting optimized values, we attempted to tune PL spectra within the blue-green region $(420-520 \mathrm{~nm})$ via systematic variation of $\mathrm{Br} / \mathrm{Cl}$ ratios. Figure $4 \mathrm{~g}$ demonstrates how the PL peak of $\mathrm{FAPb}\left(\mathrm{Cl}_{1-x} \mathrm{Br}_{x}\right)_{3} \mathrm{NCs}$ can be controllably tuned between 465 and $520 \mathrm{~nm}$ through continuous variation of Br loading from 40 to $95 \%$, while maintaining a fwhm of $26-$ $28 \mathrm{~nm}$. At the same time, we observed a decrease in fwhm for Br-rich perovskites (Figure 4h) and, conversely, PL intensity drops for high $\mathrm{Cl}$ content (Figure S4). In the Cl-rich region, all FA-to-Pb molar ratios tested yielded poor PL between 420 and $450 \mathrm{~nm}$. This is in agreement with a recent study by Levchuk et al., where the QYs of $\mathrm{Cl} / \mathrm{Br}$ perovskites with $\mathrm{Cl}$ loadings higher than $60 \%$ drop significantly from 26 to $1 \%{ }^{66}$

With a view to finding an alternate path to stable compositions with $\mathrm{Cl}$ loadings above $60 \%$, we conducted reactions with the concurrent incorporation of $\mathrm{Cs}^{+}$into the reaction solution. It is well-known that incorporation of $\mathrm{Cs}^{+}$ into $\mathrm{FAPbI}_{3}$ and $\mathrm{FAPb}(\mathrm{Br} / \mathrm{I})_{3}$ or, conversely, FA into $\mathrm{CsPbI}_{3}$ lattice can stabilize the desired 3D-perovskite phases (cubic or orthorhombic) through adjustment of perovskite tolerance factors and the added effect of the entropy of mixing. ${ }^{85-87}$ To this end, loading of $\mathrm{Cs}^{+}$into the reaction solution was performed for various $\mathrm{FA}-$ to- $\mathrm{Pb}$ molar ratios and $\mathrm{Br}$ contents. Significantly, addition of $\mathrm{Cs}^{+}$resulted in a blue shift of the emission spectrum (Figure S5) for all FA-to- $\mathrm{Pb}$ molar ratios and $\mathrm{Br}$ loadings, whereas emission maxima were tunable between $450(63 \% \mathrm{Br})$ and $520(90 \% \mathrm{Br}) \mathrm{nm}$. However, the emission intensity drastically decreases as more $\mathrm{Cs}^{+}$is incorporated and in some cases secondary peaks emerge, indicating the potential formation of a mixture of compositions, such as impurity $\mathrm{CsPb}(\mathrm{Cl} / \mathrm{Br})_{3}$ NCs. Given the significantly lower observed PL intensities of the synthesized mixed-cation $\mathrm{NCs}$ and the concurrent formation of $\mathrm{CsPb}(\mathrm{Cl} / \mathrm{Br})_{3} \mathrm{NCs}$ under the tested reaction conditions, we conclude that stable 
blue-emitting $\mathrm{Cs}_{x} \mathrm{FA}_{1-x} \mathrm{~Pb}(\mathrm{Cl} / \mathrm{Br})_{3}$ cannot be obtained using the specific methodology.

Finally, the optimized conditions for preparing FAPb$\left(\mathrm{Cl}_{1-x} \mathrm{Br}_{x}\right)_{3} \mathrm{NCs}$ in a microfluidic setup were adapted to a standard flask-based synthesis, demonstrating excellent transference (Figure 5). As an example, a precursor solution is

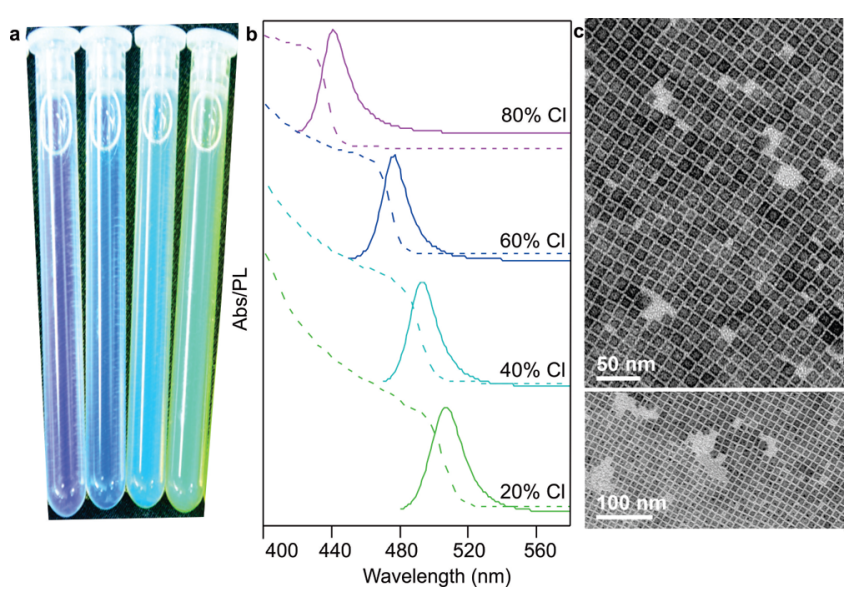

Figure 5. (a) Photograph under UV-irradiation $(365 \mathrm{~nm})$ of $\mathrm{FAPb}\left(\mathrm{Cl}_{1-x} \mathrm{Br}_{x}\right)_{3} \mathrm{NCs}$ presented in Figure panel b. (b) Absorption and emission of $\mathrm{FAPb}\left(\mathrm{Cl}_{1-x} \mathrm{Br}_{x}\right)_{3} \mathrm{NCs}$ with $20 \%, 40 \%, 60 \%, 80 \%$ of $\mathrm{Cl}$ related to the total halide content. (c) Typical TEM images for $\mathrm{FAPb}\left(\mathrm{Br}_{0.8} / \mathrm{Cl}_{0.2}\right)_{3} \mathrm{NCs}$.

prepared by dissolving $0.2 \mathrm{mmol} \mathrm{Pb}$ acetate and $1.14 \mathrm{mmol} \mathrm{FA}$ acetate in a mixture of $8 \mathrm{~mL}$ octadecene and $2 \mathrm{~mL}$ OA. Cubic $\mathrm{FAPb}\left(\mathrm{Cl}_{1-x} \mathrm{Br}_{x}\right)_{3} \mathrm{NCs}$ are then obtained upon injection of 0.8 mmol OlAmBr and $\mathrm{OlAmCl}$ (in $2 \mathrm{~mL}$ of toluene as a solvent) into this precursor solution. Intense PL was observed for NCs with chloride content up to $60 \%$. For higher chloride contents, a colored dispersion was obtained upon hot injection of $\mathrm{OlAm}(\mathrm{Br}, \mathrm{Cl})$ into the precursor solution, which, however decomposed rapidly. In agreement, with microfluidic screening PL spectra, QYs, and XRD patterns of the NCs obtained with high $\mathrm{Cl}$ ratios point to the same trend, that is, fast decomposition of the initial particles into nonluminescent $\mathrm{FAPbCl}_{3}(\mathrm{QY}<1 \%)$ and Br-rich $\mathrm{FAPb}(\mathrm{Cl} / \mathrm{Br})_{3} \mathrm{NCs}$ (Figures $\mathrm{S} 6$ and S7). This shows that a higher content of $\mathrm{Cl}$ atoms in the $\mathrm{FAPbBr}_{3}$ structure (above 40\%) will induce fast halide ion segregation and therefore instability in optical properties (Figures S7 and S8).

In conclusion, we have demonstrated that $\mathrm{FAPbX}_{3}(\mathrm{X}=\mathrm{Br}$, $\mathrm{Cl}$ ) NCs with tunable emission between 440 to $515 \mathrm{~nm}$ can be synthesized in a microfluidic platform. Use of an automated droplet-based microfluidic reactor allowed for the thorough screening of reaction parameters and elucidation of optimum $\mathrm{Cl} / \mathrm{Br}$ compositions ( $\mathrm{Br}$ content higher than 60\%) and transferral to conventional flask reactors for reaction upscaling. Significantly, automated microfluidic screening and offline structural characterization revealed that production of $\mathrm{Cl}$ rich (>60\%) $\mathrm{FAPbX}_{3}$ NCs with high PL emission poses a challenge due to the propensity of such NCs to segregate halide ions. Importantly, we also unveiled the synthetic boundaries for distinguishing between the formation of NCs $\left(T>50{ }^{\circ} \mathrm{C}\right.$, FAto- $\mathrm{Pb}>2$ ) and NPLs (room temperature, FA-to- $\mathrm{Pb}<1.5$, free oleic acid addition). Further optimization of the proposed synthetic protocols will include an investigation of the effect of
OA:OLA ratio on the resulting crystals and incorporation of other cations into the crystal structure.

\section{ASSOCIATED CONTENT}

\section{S Supporting Information}

The Supporting Information is available free of charge on the ACS Publications website at DOI: 10.1021/acs.nanolett.7b04838.

Further experimental details, emission and absorption spectra, TEM images, and XRD patterns of FAPb$\left(\mathrm{Cl}_{1-x} \mathrm{Br}_{x}\right)_{3} \mathrm{NCs}$ (PDF)

\section{AUTHOR INFORMATION}

\section{Corresponding Authors}

*E-mail: mvkovalenko@ethz.ch.

*E-mail: andrew.demello@chem.ethz.ch.

ORCID

Ioannis Lignos: 0000-0002-6816-3290

Loredana Protesescu: 0000-0002-9776-9881

Richard Maceiczyk: 0000-0001-5735-2689

Maksym V. Kovalenko: 0000-0002-6396-8938

Andrew J. deMello: 0000-0003-1943-1356

\section{Present Addresses}

"(I.L.) Department of Chemical Engineering, Massachusetts Institute of Technology, 77 Massachusetts Avenue, Cambridge, MA 02139, U.S.A.

${ }^{\perp}$ (L.P.) Department of Chemistry, Massachusetts Institute of Technology, 77 Massachusetts Avenue, Cambridge, MA 02139, U.S.A.

Notes

The authors declare no competing financial interest.

\section{ACKNOWLEDGMENTS}

The authors thank Nadia Schwitz for photographic assistance.

\section{REFERENCES}

(1) Sutherland, B. R.; Sargent, E. H. Nat. Photonics 2016, 10, 295302.

(2) Huang, H.; Polavarapu, L.; Sichert, J. A.; Susha, A. S.; Urban, A. S.; Rogach, A. L. NPG Asia Mater. 2016, 8, e328.

(3) Kovalenko, M. V.; Bodnarchuk, M. I. Chimia 2017, 71, 461-470.

(4) Kovalenko, M. V.; Protesescu, L.; Bodnarchuk, M. I. Science 2017, 358,745 .

(5) Li, X.; Wu, Y.; Zhang, S.; Cai, B.; Gu, Y.; Song, J.; Zeng, H. Adv. Funct. Mater. 2016, 26, 2435-2445.

(6) Perumal, A.; Shendre, S.; Li, M. J.; Tay, Y. K. E.; Sharma, V. K.; Chen, S.; Wei, Z. H.; Liu, Q.; Gao, Y.; Buenconsejo, P. J. S.; Tan, S. T.; Gan, C. L.; Xiong, Q.; Sum, T. C.; Demir, H. V. Sci. Rep. 2016, 6, 36733.

(7) Kim, Y.-H.; Cho, H.; Lee, T.-W. Proc. Natl. Acad. Sci. U. S. A. 2016, 113, 11694-11702.

(8) Ramasamy, P.; Lim, D. H.; Kim, B.; Lee, S. H.; Lee, M. S.; Lee, J. S. Chem. Commun. 2016, 52, 2067-2070.

(9) Pan, J.; Sarmah, S. P.; Murali, B.; Dursun, I.; Peng, W.; Parida, M. R.; Liu, J.; Sinatra, L.; Alyami, N.; Zhao, C.; Alarousu, E.; Ng, T. K.; Ooi, B. S.; Bakr, O. M.; Mohammed, O. F. J. Phys. Chem. Lett. 2015, 6, 5027-5033.

(10) Swarnkar, A.; Marshall, A. R.; Sanehira, E. M.; Chernomordik, B. D.; Moore, D. T.; Christians, J. A.; Chakrabarti, T.; Luther, J. M. Science 2016, 354, 92-95.

(11) Akkerman, Q. A.; Gandini, M.; Di Stasio, F.; Rastogi, P.; Palazon, F.; Bertoni, G.; Ball, J. M.; Prato, M.; Petrozza, A.; Manna, L. Nat. Energy 2016, 2, 16194. 
(12) Sanehira, E. M.; Marshall, A. R.; Christians, J. A.; Harvey, S. P.; Ciesielski, P. N.; Wheeler, L. M.; Schulz, P.; Lin, L. Y.; Beard, M. C.; Luther, J. M. Sci. Adv. 2017, 3, eaao4204.

(13) Protesescu, L.; Yakunin, S.; Bodnarchuk, M. I.; Krieg, F.; Caputo, R.; Hendon, C. H.; Yang, R. X.; Walsh, A.; Kovalenko, M. V. Nano Lett. 2015, 15, 3692-3696.

(14) Bai, Z. L.; Zhong, H. Z. Sci. Bull. 2015, 60, 1622-1624.

(15) Zhang, X.; Wang, H.-C.; Tang, A.-C.; Lin, S.-Y.; Tong, H.-C.; Chen, C.-Y.; Lee, Y.-C.; Tsai, T.-L.; Liu, R.-S. Chem. Mater. 2016, 28, 8493-8497.

(16) Wang, H.-C.; Lin, S.-Y.; Tang, A.-C.; Singh, B. P.; Tong, H.-C.; Chen, C.-Y.; Lee, Y.-C.; Tsai, T.-L.; Liu, R.-S. Angew. Chem., Int. Ed. 2016, 55, 7924-7929.

(17) Song, J. Z.; Li, J. H.; Li, X. M.; Xu, L. M.; Dong, Y. H.; Zeng, H. B. Adv. Mater. 2015, 27, 7162-7167.

(18) Li, J. H.; Xu, L. M.; Wang, T.; Song, J. Z.; Chen, J. W.; Xue, J.; Dong, Y. H.; Cai, B.; Shan, Q. S.; Han, B. N.; Zeng, H. B. Adv. Mater. 2017, 29, 1603885.

(19) Chiba, T.; Hoshi, K.; Pu, Y. J.; Takeda, Y.; Hayashi, Y.; Ohisa, S.; Kawata, S.; Kido, J. ACS Appl. Mater. Interfaces 2017, 9, 18054-18060.

(20) Saliba, M.; Matsui, T.; Domanski, K.; Seo, J. Y.; Ummadisingu, A.; Zakeeruddin, S. M.; Correa-Baena, J. P.; Tress, W. R.; Abate, A.; Hagfeldt, A.; Gratzel, M. Science 2016, 354, 206-209.

(21) Zhang, X. Y.; Sun, C.; Zhang, Y.; Wu, H.; Ji, C. Y.; Chuai, Y. H.; Wang, P.; Wen, S. P.; Zhang, C. F.; Yu, W. W. J. Phys. Chem. Lett. 2016, 7, 4602-4610.

(22) Pan, J.; Quan, L. N.; Zhao, Y.; Peng, W.; Murali, B.; Sarmah, S. P.; Yuan, M.; Sinatra, L.; Alyami, N. M.; Liu, J.; Yassitepe, E.; Yang, Z.; Voznyy, O.; Comin, R.; Hedhili, M. N.; Mohammed, O. F.; Lu, Z. H.; Kim, D. H.; Sargent, E. H.; Bakr, O. M. Adv. Mater. 2016, 28, 87188725 .

(23) Yoon, H. C.; Kang, H.; Lee, S.; Oh, J. H.; Yang, H.; Do, Y. R. ACS Appl. Mater. Interfaces 2016, 8, 18189-18200.

(24) Yakunin, S.; Protesescu, L.; Krieg, F.; Bodnarchuk, M. I.; Nedelcu, G.; Humer, M.; De Luca, G.; Fiebig, M.; Heiss, W.; Kovalenko, M. V. Nat. Commun. 2015, 6, 8056.

(25) Wang, Y.; Li, X. M.; Song, J. Z.; Xiao, L.; Zeng, H. B.; Sun, H. D. Adv. Mater. 2015, 27, 7101-7108.

(26) Schmidt, L. C.; Pertegas, A.; Gonzalez-Carrero, S.; Malinkiewicz, O.; Agouram, S.; Espallargas, G. M.; Bolink, H. J.; Galian, R. E.; PerezPrieto, J. J. Am. Chem. Soc. 2014, 136, 850-853.

(27) Kang, J.; Wang, L. W. J. Phys. Chem. Lett. 2017, 8, 489-493.

(28) Guo, Y. G.; Wang, Q.; Saidi, W. A. J. Phys. Chem. C 2017, 121, $1715-1722$.

(29) ten Brinck, S.; Infante, I. Acs Energy Lett. 2016, 1, 1266-1272.

(30) Shen, H.; Cao, W.; Shewmon, N. T.; Yang, C.; Li, L. S.; Xue, J. Nano Lett. 2015, 15, 1211-1216.

(31) Tan, Z. N.; Zhang, F.; Zhu, T.; Xu, J.; Wang, A. Y.; Dixon, D.; Li, L. S.; Zhang, Q.; Mohney, S. E.; Ruzyllo, J. Nano Lett. 2007, 7, 3803-3807.

(32) Bae, W. K.; Kwak, J.; Lim, J.; Lee, D.; Nam, M. K.; Char, K.; Lee, C.; Lee, S. Nanotechnology 2009, 20, 075202.

(33) Steckel, J. S.; Zimmer, J. P.; Coe-Sullivan, S.; Stott, N. E.; Bulovic, V.; Bawendi, M. G. Angew. Chem., Int. Ed. 2004, 43, 21542158.

(34) Chen, O.; Wei, H.; Maurice, A.; Bawendi, M.; Reiss, P. MRS Bull. 2013, 38, 696-702.

(35) Shirasaki, Y.; Supran, G. J.; Bawendi, M. G.; Bulović, V. Nat. Photonics 2013, 7, 13-23.

(36) Hanusch, F. C.; Wiesenmayer, E.; Mankel, E.; Binek, A.; Angloher, P.; Fraunhofer, C.; Giesbrecht, N.; Feckl, J. M.; Jaegermann, W.; Johrendt, D.; Bein, T.; Docampo, P. J. Phys. Chem. Lett. 2014, 5, 2791-2795.

(37) Protesescu, L.; Yakunin, S.; Bodnarchuk, M. I.; Bertolotti, F.; Masciocchi, N.; Guagliardi, A.; Kovalenko, M. V. J. Am. Chem. Soc. 2016, 138, 14202-14205.

(38) Hassan, Y.; Song, Y.; Pensack, R. D.; Abdelrahman, A. I.; Kobayashi, Y.; Winnik, M. A.; Scholes, G. D. Adv. Mater. 2016, 28, 566-573.
(39) Chen, X.; Peng, L. C.; Huang, K. K.; Shi, Z.; Xie, R. G.; Yang, W. S. Nano Res. 2016, 9, 1994-2006.

(40) Tong, Y.; Bladt, E.; Ayguler, M. F.; Manzi, A.; Milowska, K. Z.; Hintermayr, V. A.; Docampo, P.; Bals, S.; Urban, A. S.; Polavarapu, L.; Feldmann, J. Angew. Chem., Int. Ed. 2016, 55, 13887-13892.

(41) Yassitepe, E.; Yang, Z. Y.; Voznyy, O.; Kim, Y.; Walters, G.; Castañeda, J. A.; Kanjanaboos, P.; Yuan, M. J.; Gong, X. W.; Fan, F. J.; Pan, J.; Hoogland, S.; Comin, R.; Bakr, O. M.; Padilha, L. A.; Nogueira, A. F.; Sargent, E. H. Adv. Funct. Mater. 2016, 26, 8757-8763.

(42) Zhang, D. D.; Eaton, S. W.; Yu, Y.; Dou, L. T.; Yang, P. D. J. Am. Chem. Soc. 2015, 137, 9230-9233.

(43) Zhang, D. D.; Yang, Y. M.; Bekenstein, Y.; Yu, Y.; Gibson, N. A.; Wong, A. B.; Eaton, S. W.; Kornienko, N.; Kong, Q.; Lai, M. L.; Alivisatos, A. P.; Leone, S. R.; Yang, P. D. J. Am. Chem. Soc. 2016, 138, $7236-7239$

(44) Zhang, D. D.; Yu, Y.; Bekenstein, Y.; Wong, A. B.; Alivisatos, A. P.; Yang, P. D. J. Am. Chem. Soc. 2016, 138, 13155-13158.

(45) Tyagi, P.; Arveson, S. M.; Tisdale, W. A. J. Phys. Chem. Lett. 2015, 6, 1911-1916.

(46) Weidman, M. C.; Seitz, M.; Stranks, S. D.; Tisdale, W. A. ACS Nano 2016, 10, 7830-7839.

(47) Bekenstein, Y.; Koscher, B. A.; Eaton, S. W.; Yang, P. D.; Alivisatos, A. P. J. Am. Chem. Soc. 2015, 137, 16008-16011.

(48) Shamsi, J.; Dang, Z. Y.; Bianchini, P.; Canale, C.; Di Stasio, F.; Brescia, R.; Prato, M.; Manna, L. J. Am. Chem. Soc. 2016, 138, 72407243.

(49) Akkerman, Q. A.; Motti, S. G.; Kandada, A. R. S.; Mosconi, E.; D'Innocenzo, V.; Bertoni, G.; Marras, S.; Kamino, B. A.; Miranda, L.; De Angelis, F.; Petrozza, A.; Prato, M.; Manna, L. J. Am. Chem. Soc. 2016, 138, 1010-1016.

(50) Akkerman, Q. A.; D’Innocenzo, V.; Accornero, S.; Scarpellini, A.; Petrozza, A.; Prato, M.; Manna, L. J. Am. Chem. Soc. 2015, 137, 10276-10281.

(51) Nedelcu, G.; Protesescu, L.; Yakunin, S.; Bodnarchuk, M. I.; Grotevent, M. J.; Kovalenko, M. V. Nano Lett. 2015, 15, 5635-5640.

(52) Lignos, I.; Stavrakis, S.; Nedelcu, G.; Protesescu, L.; Demello, A. J.; Kovalenko, M. V. Nano Lett. 2016, 16, 1869-1877.

(53) Koolyk, M.; Amgar, D.; Aharon, S.; Etgar, L. Nanoscale 2016, 8, 6403-6409.

(54) Sun, S. B.; Yuan, D.; Xu, Y.; Wang, A. F.; Deng, Z. T. ACS Nano 2016, 10, 3648-3657.

(55) De Roo, J.; Ibanez, M.; Geiregat, P.; Nedelcu, G.; Walravens, W.; Maes, J.; Martins, J. C.; Van Driessche, I.; Kovalenko, M. V.; Hens, Z. ACS Nano 2016, 10, 2071-2081.

(56) Das Adhikari, S.; Dutta, S. K.; Dutta, A.; Guria, A. K.; Pradhan, N. Angew. Chem., Int. Ed. 2017, 56, 8746-8750.

(57) Liu, H. W.; Wu, Z. N.; Shao, J. R.; Yao, D.; Gao, H.; Liu, Y.; Yu, W. L.; Zhang, H.; Yang, B. ACS Nano 2017, 11, 2239-2247.

(58) Mir, W. J.; Jagadeeswararao, M.; Das, S.; Nag, A. ACS Energy Lett. 2017, 2, 537-543.

(59) Begum, R.; Parida, M. R.; Abdelhady, A. L.; Murali, B.; Alyami, N. M.; Ahmed, G. H.; Hedhili, M. N.; Bakr, O. M.; Mohammed, O. F. J. Am. Chem. Soc. 2017, 139, 731-737.

(60) van der Stam, W.; Geuchies, J. J.; Altantzis, T.; van den Bos, K. H. W.; Meeldijk, J. D.; Van Aert, S.; Bals, S.; Vanmaekelbergh, D.; de Mello Donega, C. J. Am. Chem. Soc. 2017, 139, 4087-4097.

(61) Zhumekenov, A. A.; Saidaminov, M. I.; Haque, M. A.; Alarousu, E.; Sarmah, S. P.; Murali, B.; Dursun, I.; Miao, X. H.; Abdelhady, A. L.; Wu, T.; Mohammed, O. F.; Bakr, O. M. ACS Energy Lett. 2016, 1, $32-$ 37.

(62) Ayguler, M. F.; Weber, M. D.; Puscher, B. M. D.; Medina, D. D.; Docampo, P.; Costa, R. D. J. Phys. Chem. C 2015, 119, 12047-12054.

(63) Stoumpos, C. C.; Kanatzidis, M. G. Acc. Chem. Res. 2015, 48, 2791-2802.

(64) Protesescu, L.; Yakunin, S.; Kumar, S.; Bar, J.; Bertolotti, F.; Masciocchi, N.; Guagliardi, A.; Grotevent, M.; Shorubalko, I.; Bodnarchuk, M. I.; Shih, C. J.; Kovalenko, M. V. ACS Nano 2017, 11, 3119-3134. 
(65) Minh, D. N.; Kim, J.; Hyon, J.; Sim, J. H.; Sowlih, H. H.; Seo, C.; Nam, J.; Eom, S.; Suk, S.; Lee, S.; Kim, E.; Kang, Y. Chem. Mater. 2017, 29, 5713-5719.

(66) Levchuk, I.; Osvet, A.; Tang, X.; Brandl, M.; Perea, J. D.; Hoegl, F.; Matt, G. J.; Hock, R.; Batentschuk, M.; Brabec, C. J. Nano Lett. 2017, 17, 2765-2770.

(67) Hills-Kimball, K.; Nagaoka, Y.; Cao, C.; Chaykovsky, E.; Chen, O. J. Mater. Chem. C 2017, 5, 5680-5684.

(68) Chen, D.; Chen, X.; Wan, Z.; Fang, G. ACS Appl. Mater. Interfaces 2017, 9, 20671-20678.

(69) Jang, D. M.; Kim, D. H.; Park, K.; Park, J.; Lee, J. W.; Song, J. K. J. Mater. Chem. C 2016, 4, 10625-10629.

(70) Kim, Y.-H.; Lee, G.-H.; Kim, Y.-T.; Wolf, C.; Yun, H. J.; Kwon, W.; Park, C. G.; Lee, T. W. Nano Energy 2017, 38, 51-58.

(71) Weidman, M. C.; Goodman, A. J.; Tisdale, W. A. Chem. Mater. 2017, 29, 5019-5030.

(72) Kumar, S.; Jagielski, J.; Kallikounis, N.; Kim, Y. H.; Wolf, C.; Jenny, F.; Tian, T.; Hofer, C. J.; Chiu, Y. C.; Stark, W. J.; Lee, T. W.; Shih, C. J. Nano Lett. 2017, 17, 5277-5284.

(73) Abolhasani, M.; Coley, C. W.; Xie, L. S.; Chen, O.; Bawendi, M. G.; Jensen, K. F. Chem. Mater. 2015, 27, 6131-6138.

(74) Lignos, I.; Protesescu, L.; Stavrakis, S.; Piveteau, L.; Speirs, M. J.; Loi, M. A.; Kovalenko, M. V.; deMello, A. J. Chem. Mater. 2014, 26, 2975-2982.

(75) Lignos, I.; Stavrakis, S.; Kilaj, A.; deMello, A. J. Small 2015, 11, 4009-4017.

(76) Maceiczyk, R. M.; Bezinge, L.; deMello, A. J. React. Chem. Eng. 2016, 1, 261-271.

(77) Maceiczyk, R. M.; deMello, A. J. J. Phys. Chem. C 2014, 118, 20026-20033.

(78) Nightingale, A. M.; Krishnadasan, S. H.; Berhanu, D.; Niu, X.; Drury, C.; McIntyre, R.; Valsami-Jones, E.; deMello, J. C. Lab Chip 2011, 11, 1221-1227.

(79) Yashina, A.; Lignos, I.; Stavrakis, S.; Choo, J.; DeMello, A. J. J. Mater. Chem. C 2016, 4, 6401-6408.

(80) Lignos, I.; Maceiczyk, R.; deMello, A. J. Acc. Chem. Res. 2017, $50,1248-1257$.

(81) Maceiczyk, R. M.; Lignos, I. G.; deMello, A. J. Curr. Opin. Chem. Eng. 2015, 8, 29-35.

(82) Phillips, T. W.; Lignos, I. G.; Maceiczyk, R. M.; deMello, A. J.; deMello, J. C. Lab Chip 2014, 14, 3172-3180.

(83) Maceiczyk, R. M.; Dümbgen, K.; Lignos, I.; Protesescu, L.; Kovalenko, M. V.; deMello, A. J. Chem. Mater. 2017, 29, 8433-8439.

(84) Shriner, R. L.; Neumann, F. W. Chem. Rev. 1944, 35, 351-425.

(85) Li, Z.; Yang, M. J.; Park, J. S.; Wei, S. H.; Berry, J. J.; Zhu, K. Chem. Mater. 2016, 28, 284-292.

(86) McMeekin, D. P.; Sadoughi, G.; Rehman, W.; Eperon, G. E.; Saliba, M.; Horantner, M. T.; Haghighirad, A.; Sakai, N.; Korte, L.; Rech, B.; Johnston, M. B.; Herz, L. M.; Snaith, H. J. Science 2016, 351, 151-155.

(87) Saliba, M.; Matsui, T.; Seo, J. Y.; Domanski, K.; Correa-Baena, J. P.; Nazeeruddin, M. K.; Zakeeruddin, S. M.; Tress, W.; Abate, A.; Hagfeldt, A.; Gratzel, M. Energy Environ. Sci. 2016, 9, 1989-1997. 